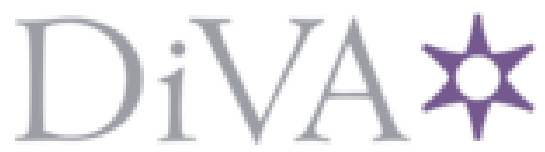

http://www.diva-portal.org

\title{
Postprint
}

This is the accepted version of a paper presented at RE@Next! track of 24th IEEE International Requirements Engineering Conference (RE'16).

Citation for the original published paper:

Fricker, S., Wallmüller, E., Paschen, I. (2016)

Requirements Engineering as Innovation Journalism: A Research Preview. In:

N.B. When citing this work, cite the original published paper.

Permanent link to this version:

http://urn.kb.se/resolve?urn=urn:nbn:se:bth-13473 


\section{Requirements Engineering as Innovation Journalism: A Research Preview}

\author{
Samuel A. Fricker \\ FHNW \\ i4Ds Centre for Requirements Engineering \\ Windisch, Switzerland \\ samuel.fricker@fhnw.ch \\ Blekinge Institute of Technology \\ SERL-Sweden \\ Karlskrona, Sweden \\ samuel.fricker@bth.se
}

\author{
Ernest Wallmüller \\ Qualität \& Informatik \\ Geroldswil, Switzerland \\ wallmueller@itq.ch
}

\author{
Ina Paschen \\ Zuehlke Engineering AG \\ Schlieren, Switzerland \\ ina.paschen@zuehlke.com
}

\begin{abstract}
The successful launch of an innovation project depends on an attractive vision and how well the vision is supported by the complementary capabilities of the consortium partners that want to cooperate to realize the vision. Alas, for an innovator the search for the right partners and visions can be lengthy and difficult. Even though the analysis of context and problem, the identification of stakeholders, the analysis of stakeholder goals and technological capabilities, and the definition of requirements belong to the cornerstones of requirements engineering, this requirements engineering problem has hardly been explored so far. In an attempt to avoid re-invention of well-tried solutions, we discovered journalism as a discipline that, as a rich body of methodical knowledge, may act as a source for the guidance of how a requirements engineer may support the launch of innovation projects. In the role of a journalist, the requirements engineer makes partners and their capabilities visible and thereby allows the parties to identify each other and meet. The transparency that develops between the parties becomes an instrument for consortia to emerge and to eventually answer calls for innovation with appropriate visions for innovation projects. This paper introduces the problem of initiating innovation projects and describes the potential role of journalism as a metaphor for addressing the problem. The paper also describes our plans in designing an innovation journalism approach that we hope will enable requirements engineers to increase innovation potential and ease the launch of projects that bring about these innovations.
\end{abstract}

Index Terms - innovation, journalism, stakeholder discovery, vision-building, design sciences research.

\section{INTRODUCTION}

Many understand the innovation process as a strategic activity that spans the phases of generating ideas, selecting an appropriate innovation candidate, and implementing the innovation [1]. A plethora of definitions exists for innovation [2] and for the degrees of innovativeness that are often termed radical, really new, and incremental [3]. Common to the many views that are represented by these definitions is the creation of something new: the innovation. Differentiating between the views is the degree of novelty and the desired impact of that novelty. Radically new things are introduced by organizations in attempts to disrupt markets with fundamental changes to technologies or how the technologies are exploited. Incremental innovations are used to maintain the status quo by adapting their offerings to the changing context or market conditions.

To innovate successfully, widely recognized 'best practices' have been proposed [4]: ideas should be screened, markets and technologies assessed, business cases analyzed, and the new products developed and tested before they are launched. According to interviews with several hundred managers responsible for new products [5], especially important for successful innovation are strategic planning for really new products and business and market opportunity analysis for incremental innovations. Strategic planning is the preliminary assessment and integration of project's resource requirements, market opportunities, and strategic directives. Business and market opportunity analysis is the conversion of ideas into a well-defined understanding of how relevant customer needs and desires may be fulfilled.

Historically, much of the requirements engineering work has focused on elicitation, analysis, modeling, validation, and management activities that are necessary to help to realize a vision for which a development project is launched [6]. Comparably little research has been devoted to the preparation for the launch of an innovation project. Notable streams of such research are represented by Davis and Gorschek who studied continuous preproject requirements engineering in the context of product evolution with incremental innovations $[7,8]$ where feedback from the various stakeholders is obtained [9]. Research aimed at enabling more radical innovations focused on creativity [10] and how to organize the idea screening process [11].

Today, we still know very little about how to effectively support the launch of really new products or radical innovations. While the proposed ideation approaches have produced interesting results, they have not addressed an activity that, according to the empirical results of Song and Montoya-Weiss correlate significantly with innovation success. To state it bluntly, we risk generating too many ideas, but none of them may be of relevance. 
According to Song and Montoya-Weiss, what is needed instead is support for strategic planning [5]. Effective pre-project requirements engineering for a really new product should support the development of an understanding of how a product concept may be transformed into a business proposition that fits the investment budget, the timetable for the product release, the personnel to realize the project, and the expected profits and benefits.

To help the participants of the innovation process to perform such strategic planning for really new innovations, we propose the use of innovation journalism, a concept that was first proposed by Nordfors [12]. We interpret the term as the elicitation and targeted sharing of information about achieved innovations that may enable the next innovations. The objective of the approach is to bring visibility to who the parties are that may enable the innovations and what the background is they may bring into an innovation project. Partners may bring technological background that is important for rapidly developing the product or bring market business legacy that is essential for understanding the value creation for customers and how to reach the customers [13]. We conjecture that knowledge about the partners' past innovations is essential because it determines what the potential benefits, costs, and risks are that each candidate partner brings into the project and whether the idea is feasible.

This paper introduces the problem of initiating innovation projects and describes the potential role of journalism as a metaphor and a way of acting for addressing the problem. It describes our conceptualization for understanding the problem and describes the implications of the requirements engineer's innovation journalist work and outcomes. The paper also describes our plans in designing an innovation journalism approach that we hope will enable requirements engineers to increase innovation potential.

The remainder of this paper is structured as follows. Section II describes innovation journalism by introducing relevant background. Section III outlines the methodology of the research we have launched for investigating the problem, analyzing the stateof-the-art analysis, designing a method for addressing the problem, and for validating the method in practical innovation contexts. Section IV summarizes and concludes.

\section{TOWARDS ENABLING REALLY NEW INNOVATIONS}

\section{A. Resource-based Conceptualization of Innovation}

Our conceptualization of innovation draws on the resourcebased view of an organization's strategy [14]. In this view, the focal concern of the organization is the accumulation of assets that offer a strategic advantage and are difficult to be replicated or imitated by competitors. Examples of such assets are platforms for product development, facilities for provisioning of services, organizational structure and processes for product development and delivery, and knowledge about these assets and processes. Such assets are difficult to transfer because of the cost and risks such a transfer involves and because much of the knowledge is tacit.

A firm unavoidably follows a path where past innovations deliver the assets that are used to build innovations. The legacy that is produced with innovation projects, thus, delivers a strategic advantage. The closer the assets are to a future innovation, the cheaper and easier it becomes to develop that innovation. When describing cases of innovations from Ericsson, IBM, and Rorotika, Khurum reported that software components, business relationships, and business practices affected the way really new innovations were developed [13].

The resource-based view of strategy implies that an organization has limited ability to produce really new innovations. The organization does not possess all the resources to reinvent itself rapidly and address the markets with really new offerings. If it accepts to depend on partners who bring complementary background, it may be faster and more effective in bringing about the really new innovations. Fig. 1 illustrates the anatomy of such a collaboration project.

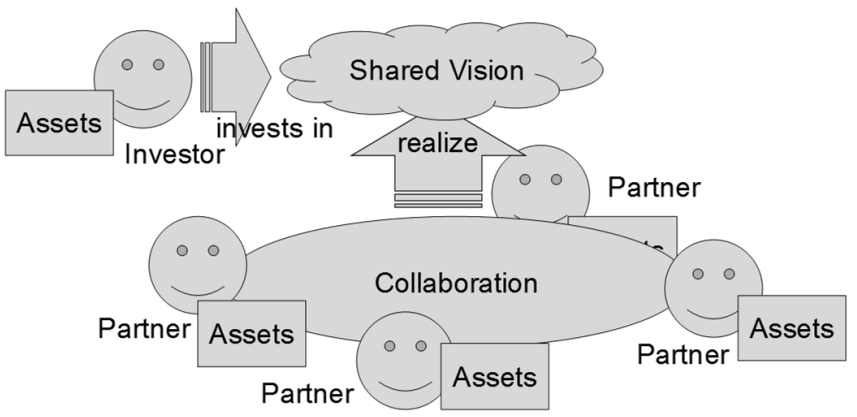

Fig. 1. Anatomy of an Innovation Project with Partners.

Chesbrough called this collaborative innovation approach the Open Innovation Model: in open innovation, a company combines its ideas with innovations from other firms [15]. The benefits of open innovation are visible in the cost and time needed to produce successful really new innovations. Also, governments invest in open innovation because it allows knowledge to circulate and be transformed into products and services that create new markets and foster entrepreneurship [16]. At the same time, the open innovation model implies challenges [17, 18]. Partners with complementary assets need to find each other and agree on a shared vision for a jointly developed innovation.

\section{B. Innovation Journalism for Partner and Asset Discovery}

Journalism is widely considered to be a public service: journalists serve as watchdogs for important events and actively collect and disseminate information [19]. A journalist is impartial, neutral, objective, fair and thus credible. At the same time, journalists have a good understanding of immediacy and have the capability to spread actual information rapidly to the communities that are affected by them.

Innovation Journalism is a recent variant of journalism. It is journalism about innovation and covers technical, business, legal, and political aspects of innovations [12]. It is considered to be a key enabler for innovation diffusion: the spread of information about innovation to enable the use and appropriation of the innovation [20]. Despite growing recognition, the many uses of this journalistic approach are still under investigation [21].

In our opinion, the enablement of the search for partners and the partners' backgrounds is an underdeveloped but crucial use 
case for innovation journalism. It is a form of journalism that directs the diffusion of innovations towards those who may benefit and build on the diffused innovations with again new innovation projects. In the role of a journalist, the requirements engineer makes partners and their backgrounds visible and thereby allows the parties to identify each other. The transparency that develops between the parties becomes an instrument for consortia to emerge and to eventually answer calls for innovation with appropriate visions for innovation projects.

Our view of innovation journalism resembles science journalism. A science journalist is a public intellectual that monitors scientists and institutions, explains the methods and results of science, contributes to setting research agendas, and connects and brings together scientists and non-specialists [22]. While the activities are similar, the innovation journalist concentrates on identified challenges and explored technologies for addressing these challenges and facilitates the creation of new innovations.

The widely established exploration and exploitation model in organizational learning [23] may be used as a basis for guiding innovation journalism methodologically. Fig. 2 illustrates the model. According to the model, new possibilities are created by trading exploration off with exploitation. Exploration includes things captured by terms such as search, experimentation, play, and discovery. Exploitation includes things like choice, implementation, and execution. Mapped to the problem of enabling really new innovations, the model suggests that exploration should bring transparency into potential partners and the backgrounds they may bring into an innovation project. A journalist may support that search, as one of the possible concrete outcomes, with articles, photo stories, or movies that portray these innovations and the people and organizations behind them. Exploitation should involve the definition of a vision for an innovation project that is shared by selected partners and the execution of that innovation project. An innovation journalist may support that vision-building by supporting the curation of events where potential innovation partners meet and by facilitating a win-win dialogue between the participating parties.

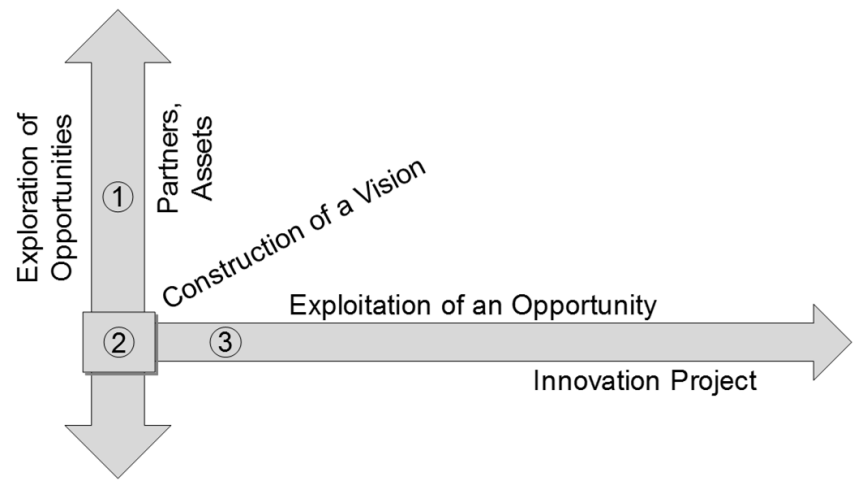

Fig. 2. Exploration - Exploitation Trade-off: (1) exploration of opportunities, (2) idea selection and vision-building, (3) exploitation of an opportunity.

The toolset available to requirements engineers is applicable for innovation journalism: the analysis of context and problems, the identification of stakeholders, the analysis of the scenarios of how technological capabilities deliver stakeholder benefits be- long to the corner-stones of requirements engineering. In a similar vein, a requirements engineer is trained to document and communicate technical topics to a wide audience of stakeholders that are affected by these topics. These abilities are tools needed to support exploration and exploitation activities.

To measure the success of innovation journalism the construct of absorptive capacity [24] may become useful. Zahra and George's model suggests that an organization's innovative output relates significantly to the organization's acquisition of prior investments, knowledge and network, the organization's assimilation of these assets, the transformation of these assets in innovation projects, and the exploitation of the resulting innovations. The former two components reflect the organization's potential absorptive capacity, i.e. the organization's ability to explore opportunities. The latter two components reflect the organization's realized ability to exploit the opportunities. A successful innovation journalist will measurably increase an organization's absorptive capacity, thus, significantly improve the organization's ability to innovate successfully. Innovation journalism may be falsified as model of thinking and acting by comparing it with alternative approaches to build absorptive capacity.

\section{RESEARCH GOALS, QUESTIONS, AND METHOD}

To realize our vision, we propose to develop a journalismbased approach for helping organizations in pre-innovation situations to launch more and better really new innovation projects. The approach will be embodied in a method that makes innovation journalism feasible and allows us to study it. We intend to evaluate the method iteratively by studying its impact on the absorptive capacity of the stakeholders that are interested in coinnovating, both in laboratory and real-world contexts. The successes of the method will be a means to highlight the potential of the innovation journalism. Failures, which do not necessarily need to be mutually exclusive to successes, will be opportunities to learn and better understand innovation enablement.

The overall research approach follows Wieringa's Design Science Methodology [25]. We have split the research into three phases. Each phase is guided by a main research question (RQ) or a design task (DT). The research aims at answering the following research questions:

RQ1. What are the current challenges of initiating innovation projects?

RQ2. What are the current approaches for enhancing the absorptive capacity of the innovation stakeholders?

DT3. Tailor journalism to enhance the creation of consortia and visions for innovations!

RQ4. What are the obstacles, benefits, and limitations of innovation journalism?

The remainder of this section describes how we plan to answer the research questions RQ1, RQ2, and RQ4 and perform the design DT3. As the design and validation research for DT3 and RQ4 depends on the answers for RQ1 and RQ2, we focus the descriptions on how we answer RQ1 and RQ2 and outline the principles that guide our approach for DT3 and RQ4. 


\section{A. Challenges of Innovation Project Initiation}

The answer to the first research question will be a rich, qualitative description of challenges launching open innovation projects. The challenges may include confidentiality of knowledge and abilities, regulatory limitations, compatibility of the organizations, conflicts with internal strategic objectives, effort, and power relationships. Such answers can be obtained by studying the experiences of people in preparing and launching an innovation project. It will be important to study both successes and failures as both are essential for learning [26]. To understand what factors contributed to innovation project success or failure, retrospective analyzes of the experiences are useful. These retrospectives should be complemented with case studies that aim at understanding the challenges as they unfold, thus help us to avoid biased sense-making in hindsight [27].

An important threat to validity of such research concerns external validity. Phenomena central for the environment inside a company may not work in a context where different types of organizations come together from different domains. We intend to achieve such representativeness by covering the expected variations of important pre-innovation contexts and perspectives on innovation projects with a stratified sampling approach [28]. Table I shows such a sampling. The stratified sampling approach will enable triangulation, hence analysis of similarities and differences of the obtained results across contexts and perspectives, thus showing what generalized and what not.

TABLE I. Stratified SAMPLING APPROACH (X REPRESENTS STRATA)

\begin{tabular}{|l|c|c|c|}
\hline \multirow{2}{*}{ Pontext } & \multirow{2}{*}{ Perspective } & \multirow{2}{*}{ Investor } & \multicolumn{2}{|c|}{ Consortium Partner } \\
\cline { 3 - 4 } & & Leader & Member \\
\hline Corporate & $\mathrm{X}$ & $\mathrm{X}$ & $\mathrm{X}$ \\
\hline Vertical, industry-specific & $\mathrm{X}$ & $\mathrm{X}$ & $\mathrm{X}$ \\
\hline Horizontal, society level & $\mathrm{X}$ & $\mathrm{X}$ & $\mathrm{X}$ \\
\hline
\end{tabular}

Other threats to validity are construct and internal validity. They are concerned of whether we observe what we intend to research and whether causal conclusions are warranted. In particular, an innovation project may be considered to be successful by some and, at the same time, a failure by others. For collecting data, we plan to use semi-structured interviews. In the beginning, we anchor the interviewee in the right context by letting the interviewee report about a recent or current experience in preparing and launching an innovation project. Once the case is sufficiently elaborated, we let the interviewee report about success factors and criteria innovation project launch, while relating back to the experience. The third part of the interview are reflections about how to measure the potential for innovation and the factors that affect that potential. The use of the anchor during the middle and final parts of the interview will help us to manage construct and internal validity as the anchor helps to relate the interviewee's reflections to concrete, multifaceted experiences.

For answering the research question RQ1, the collected, transcribed data will be analyzed with content analysis [29]. Provided that the theoretical background described in Section II is a good fit for explaining the experiences of the interviewee's, we will use directed content analysis. Alternatively, we develop a synthesis of goals, challenges, approaches, and success criteria directly from the transcripts by applying conventional content analysis. We anticipate that the key threat to validity in this stage will be reliability that we address by maintaining a full chain of evidence, peer debriefing, and member checking.

\section{B. State-of-the-Art for Building Absorptive Capacity}

The answer to the second research question will be an overview of the approaches for building innovation potential. The existence of journals, conference, and a plethora of books devoted to the topic of innovation, we anticipate that there will be a sufficient number of published works that can be used for a systematic mapping study [30]. The focus of the study will be in understanding how innovation potential is measured, what contextual factors enable or inhibit that potential, and what the approaches have been described to build such potential. We anticipate that we will identify approaches for enabling innovation as well as for planning innovation and launching innovation projects, such as [31, 32].

As common in literature reviews in software engineering [33], we intend to use keyword-based search for identifying papers in electronic sources. We will formulate the search string by fixing the context, population, and outcomes. The context will be real-world industrial environments where innovation for or with ICT are undertaken, the population will be innovation undertakings, and the outcomes the launch of innovation projects or increased potential for innovation. With this approach, we partly follow the PICOC question structure described by Kitchenham and keep the intervention and comparison variables open for mapping. The search strategy will be developed iteratively by validating the obtained results by snowballing backward and forward from the identified papers, a search approach that is capable of identifying a set of papers orthogonal to the keyword-based approach [34].

The search string will be adapted to the variations required by the respective databases and applied on Scopus, the largest database of abstracts and citations, Inspec, ScienceDirect, and EngineeringVillage, Web of Science, IEEEExplore, and the ACM Digital Library. These databases provide good coverage of management and engineering literature, the two main domains in which we expect to find relevant work.

TABLE II. MAPPING DIMENSIONS

\begin{tabular}{|l|l|}
\hline Dimension & Expected categories \\
\hline Research & Research methods used in evaluation. \\
\hline Context & Corporate, vertical, or horizontal settings. \\
\hline Domain & Technologies for ICT systems or application domains of ICT. \\
\hline Perspective & $\begin{array}{l}\text { Investor, consortium partner, or other perspective used by the } \\
\text { research. }\end{array}$ \\
\hline Construct & Innovation potential definitions and measurement. \\
\hline Context & Factors that enable or inhibit innovation potential. \\
\hline Approach & $\begin{array}{l}\text { Processes, methods, and tools used and evaluated for building } \\
\text { innovation potential. }\end{array}$ \\
\hline
\end{tabular}

The study selection criteria will be developed with a-priori criteria and by piloting the literature review. The a-priori criteria relate to the domain of the research, which should be innovation for or with ICT, the scope of the research, which should meet the pre-innovation project stage, and the evidence provided by the papers in support of the claims. To reflect actually innovation practice in true real-world contexts, we expect evidence at least 
at the level that is produced by high-quality case study research. The team of researchers reviews a subset of the identified papers in full depth. The analysis will have the aim of discovering reasons for inclusion and exclusion that are adapted to the population of papers that is found in the research databases.

The data extraction strategy will focus on the identification of information in the dimensions that are described in Table II.

The categories for populating the mapping dimensions will be formed by keywording of abstracts [30] or by using known classification taxonomies. For example, keywording will be used for for mapping the approaches to building innovation potential. For mapping the type of research of the identified papers, the taxonomy used by Glass [35] is intended to be used. For managing the threat to validity of wrong designations of papers [36], we verify the claimed use of a research method with the method description in the body of the papers.

For answering the research question RQ2, we will characterize the categories for the construct, context factor, and approach dimensions that emerged from the papers. The characterization of the constructs will allow understanding how to measure the outcome, the characterization of the context factors how to enable innovation, and the characterization of the approaches how to build innovation capacity. An analysis will be performed to compare the uses of the approaches by the mapped perspectives and domains and to compare the effects of the approaches on innovation potential. An overview of the research frontier will be given by identifying areas of mature research and areas where high-quality research is inexistent. The results will be presented by visualizing the data we have extracted, e.g. with Bubble Plots [Petersen], by summarizing the results, e.g. with tables, and by providing in-depth descriptions of our key observations.

\section{Design and Evaluation of Innovation Journalism Method}

The treatment design for DT3 and the answer of the research question RQ4 are intertwined. The goal is to develop an innovation journalism method that solves the practical problems identified when answering RQ1 and that advances the state-of-theart. The progress of the innovation journalism approach over the state-of-the-art shall be significant when measured in terms of the absorptive capacity that is perceived by the investors and partners that are involved in innovation projects. Such significance will be important for financing the use of the method.

TABLE III. DESIgn AND VALIDATION ITERATIONS

\begin{tabular}{|c|l|l|}
\hline TRL & Design (DT3) & Validation (RQ4) \\
\hline 2 & $\begin{array}{l}\text { Design of exploration-exploitation } \\
\text { process and news portraits. }\end{array}$ & $\begin{array}{l}\text { Concept and process reviewed } \\
\text { and accepted by stakeholders. }\end{array}$ \\
\hline 4 & $\begin{array}{l}\text { Design of approach for sharing in- } \\
\text { novation portraits and exploration- } \\
\text { exploitation process. }\end{array}$ & $\begin{array}{l}\text { Action research with a commu- } \\
\text { nity interested in furthering the } \\
\text { local software industry. }\end{array}$ \\
\hline 7 & $\begin{array}{l}\text { Enhancement of the approach based } \\
\text { on lessons-learned and training of } \\
\text { innovation journalists. }\end{array}$ & $\begin{array}{l}\text { Case study research with a large- } \\
\text { scale industry partner and a verti- } \\
\text { cal community. }\end{array}$ \\
\hline 9 & $\begin{array}{l}\text { Preparation of public release with } \\
\text { approach owner and launch of } \\
\text { innovation journalism community. }\end{array}$ & $\begin{array}{l}\text { Survey-based monitoring of } \\
\text { adoption, use, and impact of the } \\
\text { innovation journalism method. }\end{array}$ \\
\hline
\end{tabular}

For developing and validating the innovation journalism treatment, we follow the technology readiness levels (TRL) framework that is recommended by the European Commission for Horizon 2020 projects $^{1}$. The TRL framework provides recommendations of how technology may be developed, matured, and released into a competitive operational environment.

During the early phases, we would like to be in control of the development and validation work. In later phases, we plan to give leeway for how the method is used and evolves. This approach reflects the recommendations of Gorschek who suggests to prepare and evaluate a method first in a laboratory setting before then transferring it to industry in a step-by-step fashion [37]. Table III gives an outline of how we map our research onto the TRL. Each row represents one research iteration.

\section{SUMMARY AND CONCLUSIONS}

In this paper, we have reported our vision of innovation journalism, an approach towards helping organizations to launch more and better projects for developing really new innovations. We have conceptualized the preparation of such innovation as the search for partners that can bring relevant assets into consortia for innovation projects. Innovation journalism is the counterpart of that search: it is an active scouting for recent innovations with the intent to disseminate knowledge of these innovations and the partners behind the innovations to other candidate partners. As a result, we conjectured that innovation journalism will significantly improve the absorptive capacity of the innovating organizations.

Inspired by the RE@Next! call,we have proposed a research project with the aim of designing the first innovation journalism method for expanding the absorptive capacity of innovating organizations. Our intention is to execute the project in close collaboration with industry to ensure relevance and effectiveness. We hope to get relevant feedback from the reviewers for anchoring the innovation journalism approach and for improving our plans early. Should the paper be accepted, the presentation at the conference would be an excellent opportunity to share our early lessons from the unfolding research and to find collaborators for scaling the work.

With our work, we hope that innovation journalism finds a place in requirements engineering research. The innovation journalist benefits from the toolset that used by requirements engineers, including the discovery of stakeholders, the analysis of how the stakeholder's background may be combined to fulfill the vision of an innovation project, and the communication of the results from these activities. At the same time, innovation journalism may inspire and extend the toolset used by the "traditional" requirements engineers. To support the creation of such a place, we have argued with the little work that so far has been devoted to the enablement of critical practices for really new innovations. 


\section{REFERENCES}

[1] R. Cooper, Winning at New Products: Accelerating the Process from Idea to Launch, 3rd ed.: B\&T, 2001.

[2] H. Edison, N. bin Ali, and R. Torkar, "Towards Innovation Measurement in the Software Industry," under revision, available upon request, 2012.

[3] R. Garcia and R. Calantone, "A critical look at technological innovation typology and innovativeness terminology: a literature review," Journal of Product Innovation Management, vol. 19, pp. 110-132, 2003.

[4] R. G. Cooper and E. J. Kleinschmidt, "An investigation into the new product process: steps, deficiencies, and impact," Journal of Product Innovation Management, vol. 3, pp. 71-85, 1986.

[5] X. M. Song and M. M. Montoya - Weiss, "Critical development activities for really new versus incremental products," Journal of Product Innovation Management, vol. 15, pp. 124-135, 1998.

[6] B. Cheng and J. Atlee, "Research Directions in Requirements Engineering," presented at the Future of Software Engineering (FOSE'07), Washington, DC, USA, 2007.

[7] A. Davis, Just Enough Requirements Management: Dorset House Publishing, 2005.

[8] T. Gorschek and C. Wohlin, "Requirements Abstraction Model," Requirements Engineering, vol. 11, pp. 79-101, 2006.

[9] I. Todoran, N. Seyff, and M. Glinz, "How Do Cloud Providers Elicit Consumer Requirements: an Exploratory Studdy of Nineteen Companies," presented at the 21th IEEE International Requirements Engineering Conference (RE'13), Rio de Janeiro, Brazil, 2013.

[10] N. Maiden, A. Gizikis, and S. Robertson, "Provoking Creativity: Imagine What Your Requirements Could Be Like," IEEE Software, vol. 21, pp. $68-75,2004$.

[11] T. Gorschek, S. Fricker, K. Palm, and S. Kunsman, "A Lightweight Innovation Process for Software-Intensive Product Development," IEEE Software, vol. 27, pp. 37-45, 2010.

[12] D. Nordfors, "The Concept of Innovation Journalism," Innovation Journalism, vol. 1, pp. 1-14, 2004.

[13] M. Khurum, S. Fricker, and T. Gorschek, "The Contextual Nature of Innovation - An Empirical Investigation of Three Software Intensive Products," Information and Software Technology, vol. 57, pp. 595-613, 2015.

[14] D. J. Teece, G. Pisano, and A. Shuen, "Dynamic Capabilities and Strategic Management," Strategic Management Journal, vol. 18, pp. 509-533, 1997.

[15] H. W. Chesbrough, "The Era of Open Innovation," MIT Sloan Management Review, vol. 44, pp. 35-41, 2003.

[16] European Commission, Open Innovation, Open Science, Open to the World - A Vision for Europe: European Union, 2016.

[17] P. Nakagaki, J. Aber, and T. Fetterhoff, "The Challenges in Implementing Open Innovation in a Global Innovation-Driven Corporation," Research Technology Management, vol. 55, pp. 32-38, 2012.

[18] B. Bigliardi and F. Galati, "Which Factors Hinder the Adoption of Open Innvoation in SMEs?," Technology Analysis and Strategic Management, vol. In Press, 2016.
[19] M. Deuze, "What is Journalism?," Journalism, vol. 6, pp. 442-464, 2005.

[20] E. Kauhanen and E. Noppari, "Innovation, Journalism and Future: Final Report of the Research Project 'Innovation Jounralism in Finland'," Tekes Technology Review, Helsinki2007.

[21] D. Nordfors, "Why We Need Innovation Journalism, and Where It May Have a Market," presented at the 1st Conference on Innovation Journalism, Stanford, CA, USA, 2004.

[22] D. Fahy and M. Nisbet, "The Science Journalist Online: Shifting Roles and Emerging Practices," Journalism, vol. 12, pp. 778-793, 2011.

[23] J. March, "Exploration and Exploitation in Organizational Learning," Organization Science, vol. 2, pp. 71-87, 1991.

[24] S. Zahra and G. George, "Absorbtive Capacity: A Review, Reconceptualization, and Extension," Academy of Management Executive, vol. 27, pp. 185-203, 2002.

[25] R. Wieringa, Deisgn Science Methodology for Information Systems and Software Engineering: Springer, 2014.

[26] S. Sitkin, "Learning Through Failure: The Strategy of Small Losses," Research in Organizational Behavior, vol. 14, pp. 231-266, 1992.

[27] P. Runeson, M. Höst, A. Rainer, and B. Regnell, Case Study Research in Software Engineering: Guidelines and Examples: John Wiley \& Sons, 2012.

[28] M. Miles and M. Huberman, Qualitative Data Analysis: An Expanded Sourcebok. California, USA: SAGE Publications, 1994.

[29] H. F. Hsieh and S. E. Shannon, "Three approaches to qualitative content analysis," Qualitative health research, vol. 15, pp. 1277-1288, 2005.

[30] K. Petersen, R. Feldt, S. Mujtaba, and M. Mattsson, "Systematic mapping studies in software engineering," presented at the 12th International Conference on Evaluation and Assessment in Software Engineering, 2008.

[31] A. Fosfuri and J. Tribó, "Exploring the Antecedents of Potential Absorbtive Capcit and Its Impact on Innovation Performance," Omega, vol. 36, pp. 173-187, 2008.

[32] M. Easterby-Smith, M. Graça, E. Antonacopoulou, and J. Ferdinand, "Absorptive Capacity: A Process Perspective," Management Learning, vol. 39, pp. 483-501, 2008.

[33] B. Kitchenham, "Guidelines for Performing Systematic Literature Reviews in Software Engineering," 2007.

[34] S. Jalali and C. Wohlin, "Systematic Literature Studies: Database Searches vs. Backward Snowballing," presented at the 8th ACM-IEEE International Symposium on Empirical Software Engineering and Measurement (ESEM 2012), Lund, Sweden, 2012.

[35] R. Glass, I. Vessey, and R. Venkataraman, "Research in Software Engineering: An Analysis of the Literature," Information and Software Technology, vol. 44, pp. 491-506, 2002.

[36] E. Mendes, "A Systematic Review of Web Engineering Research," presented at the International Symposium on Empirical Software Engineering (ISESE 20015), Noosa Heads, Australia, 2005.

[37] T. Gorschek, C. Wohlin, P. Garre, and S. Larsson, "A Model for Technology Transfer in Practice," Software, IEEE, vol. 23, pp. 88-95, 2006. 